\title{
SMEDT: UN NUEVO MARCO COMPUTACIONAL PARA EL DISEÑO SOSTENIBLE DE MAQUINARIA, CON UN CASO DE ESTUDIO
}

\section{SMEDT: A NEW COMPUTATIONAL FRAMEWORK FOR THE SUSTAINABLE DESIGN OF MACHINERY, WITH A STUDY CASE}

\author{
MEng. Jorge Enrique Meneses Flórez *, Ing. J.R. Amaya Silva ** \\ Ing. C.E. Gualdrón Arenas *, MSc. D.P. Meneses Salazar *** \\ * Universidad Industrial de Santander (UIS), Conectividad y Procesamiento de Señales. \\ Ciudad Universitaria, Bucaramanga, Santander, Colombia. \\ Tel.: (+577) 6344000 Ext. 2483/2829. \\ E-mail: jmeneses@uis.edu.co,cega088@gmail.com \\ ** Cranfield University, United Kingdom. \\ E-mail: j.amaya-silva@cranfield.ac.uk. \\ **** Universidad de los Andes, Grupo de Mecánica Computacional. \\ E-mail: dp.meneses60@uniandes.edu.co.
}

\begin{abstract}
Resumen: Los avances en la ingeniería moderna han permitido la consolidación de sistemas computacionales para el diseño óptimo de máquinas, con un proceso que se especifica en la búsqueda de estándares propios del producto a diseñar, a partir de consideraciones funcionales, estéticas y de desempeño, así como también, restricciones dimensionales en cuanto a costos, operaciones de manufactura, sustentabilidad y calidad. En el presente artículo se expone el desarrollo de una herramienta computacional modular, escalable, libre, de fácil mantenimiento e interactiva que soporta la metodología Sustainable Mechanical Design Tool (SMEDT) para el diseño de máquinas de diferente tipo, a partir del uso de dos técnicas de optimización estocástica: Optimización por Enjambre de Partículas (PSO) y Algoritmos Genéticos (GA). El caso de estudio se caracteriza por el diseño de una bomba de pistones axiales con desplazamiento fijo basado en tres parámetros de entrada (rango de presión de operación, rango de velocidad de operación y capacidad volumétrica). Para lograr el diseño sostenible, se hace uso de la metodología y herramienta computacional SMEDT, mediante dos etapas de optimización: la primera enfocada en minimizar el tamaño de la bomba; y la segunda en maximizar la eficiencia volumétrica y disminuir el ruido. Se analizan el algoritmo de optimización y parámetros de entrada para determinar su influencia en el diseño final.
\end{abstract}

Palabras clave: Bomba de Pistones Axiales de Desplazamiento Fijo, PSO, GA, Herramienta Computacional, Optimización Multi-objetivo, Simulación.

\begin{abstract}
Modern engineering advances have allowed to consolidate computational systems for the optimum design of machinery based on complex models that consider not only matching the industrial standards, but also to achieve functional, aesthetical design for manufacturing, quality and sustainability specifications. In this article, it is exposed the development of a free and an interactive modular computer-optimized design tool, SMEDT (Sustainable Mechanical Design Tool), created to support the sustainable mechanical design methodology for computer tools, an authors' proposed strategy that allows to design a diverse and broad group of machinery based on two optimization stochastic techniques: Particle Swarm Optimization (PSO) and Genetic Algorithms (GA). The case study proposed for validating the aforementioned tool was the design of a fixed
\end{abstract}


displacement swash plate axial piston pump using three input parameters (operation pressure range, operation velocity range and volumetric capacity). To achieve a sustainable design, the methodology for SMEDT and the tool were used, through a two optimization steps: the first one focused on minimizing the sizes of the pump; and then, using the output of the first step, this final stage focus on maximizing the performance (increasing efficiency vs decreasing noise) counting for the dynamic response of the pump.

Keywords: Fixed Displacement Swash Plate Axial Piston Pump, PSO, GA, Computational Framework, Multi-objective Optimization, Simulation.

\section{INTRODUCTION}

A machine's socioeconomic footprint and environmental impact during its life cycle are primarily due to the operational phase. Each year, the food and drink, automotive, and energy industries acquire and/or produce more machines to satisfy the demands of a growing population. Since acquisitions will keep growing and Greenhouse Gasses Emissions caused by those machines will cumulate in the atmosphere, global warming consequences will grow exponentially.

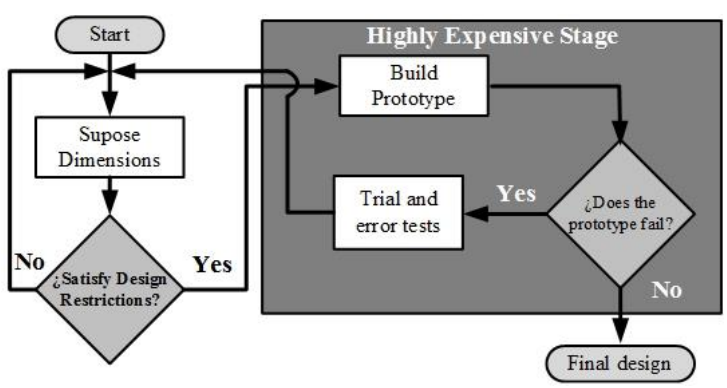

Fig. 1. Mechanical Design Traditional Approach. Adapted from [1]

The relationship between a machine's performance and its design is well established. Therefore, in order to decrease their impact, we must begin to design machines in a sustainable way. This means that the design process must simultaneously satisfy various objectives: energy efficiency, safety and reliability, economic competitiveness, and low pollution levels. Some authors [1], [2] have shown that the classical design approach (Figure 1) is unsuitable to achieve a sustainable design because it is expensive in terms of time and money, inhibits innovative solutions, and does not guarantee that an optimal design will ultimately be chosen. These

authors also proposed a computational approach that is able to successfully choose the discrete decision variables (materials, bearings, and predesigned elements) and the continuous decision variables (shapes and geometry) in more realistic and complex models using the Genetic Algorithms (GA) optimization method.

However, studies like the one described above are scarce, inflexible, and limited. Most are only capable of designing a specific machine type. Besides, the optimization and simulation methods are unchangeable. Other studies demonstrate an incomplete automation of the process. Finally, few are easily adaptable to new production techniques.

To solve those problems, in this work we proposed: (1) creating a modular computational framework to support the sustainable design decision-making process (materials selection, dimensions, and geometry). This framework allows for the complete optimization of the design of any machine over a given operating range, (2) validating the behavior of this framework in the design of a fixed displacement swash plate axial piston pump using a complex model (Table 1) and comparing the results with the literature, and (3) analyzing the outcome of the GA and PSO optimization methods on the final design.

\section{Table 1: Complexity of the Fixed Displacement Swash Plate Axial Piston Pump Design}

\section{Description}

Num. Differential Equations

Num. Model variables

Num. Independent Variables

Constraints
Value

10

$>100$

$>35$

Yes 


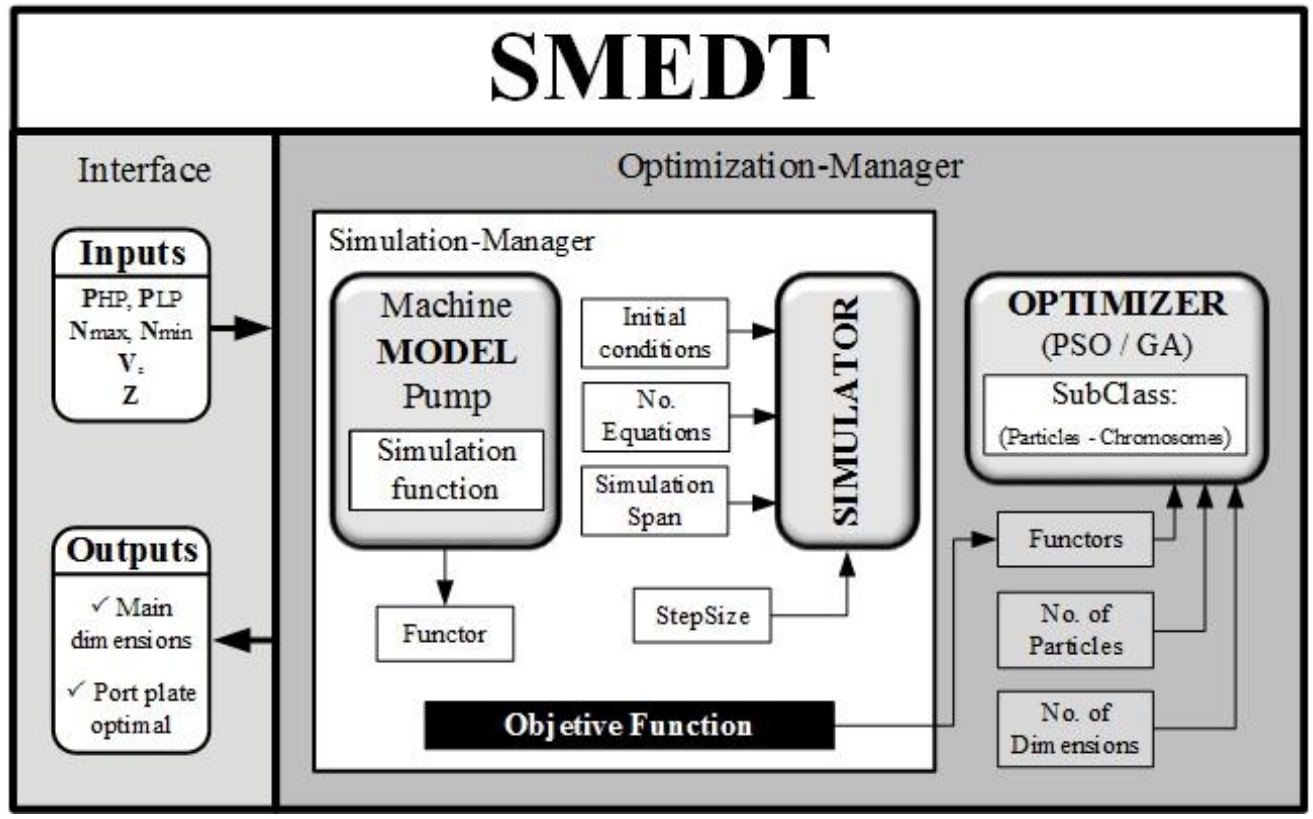

Fig. 2. SMEDT software architecture

\section{COMPUTATIONAL FRAMEWORK SMEDT}

The Sustainable Mechanical Design Tool (SMEDT) is a modular, scalable, easilymaintainable, and interactive $\mathrm{C}++$ computational framework. The tool (Figure 2) is composed of three macro modules, called the model, optimizer, and simulator modules, which are interlinked using functors. The framework has an interface for the input of parameters - which are the same parameters specified to choose a machine from a catalogue - and for the output of results.

\subsection{Optimizer module}

This is the module that contains the optimization algorithm. Two optimizers were proposed, PSO and GA, since they easily adapt to computational models and have a high efficiency in solving multiobjective engineering problems. The mechanical design process was stated as a mathematical optimization problem, minimizing the objective function $f(x)$, as follows:

Subject to:

$$
\text { Minimize } f(x)=(x)
$$

$$
\begin{aligned}
& h_{j}(x)=0 \text { for } j=1_{v \rightarrow n} m \\
& g_{k}(x) \leq 0 \text { for } k=1_{v \infty} q q
\end{aligned}
$$

Where $x$ is a vector that contains $n$ decision variables, and $h_{i}(x)$ and $g_{j}(x)$ are the $j^{\text {th }}$ and $k^{\text {th }}$ of $m$ equality constraints and $q$ inequality constraints, respectively. For the handling of constraints, a penalty function method was used. This allows us to convert a constrained problem to an unconstrained problem with a penalized objective function $F(x)$, as shown in equation (4):

$$
\begin{aligned}
F(x)=f(x)+\alpha * & \left(\sum_{i=1}^{m} \max \left(g_{i}(x), 0\right)^{n}\right. \\
& \left.+\sum_{j=1}^{\mathrm{g}} \max \left(\left|h_{j}(x)\right|, 0\right)^{\mathrm{n}}\right)
\end{aligned}
$$

With $\alpha$ being the penalization factor.

\subsubsection{Particle swarm optimization - PSO}

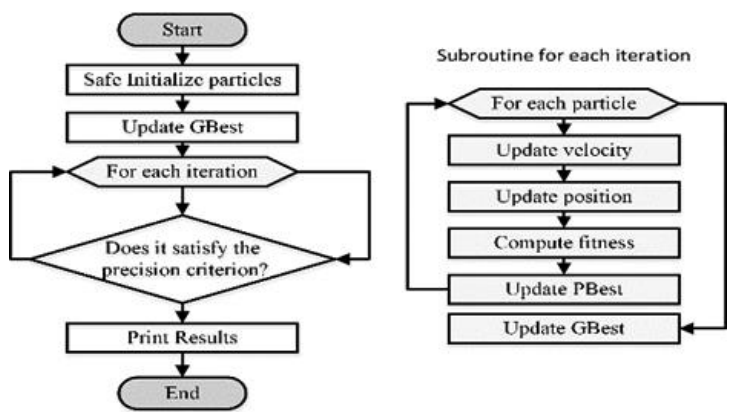

Fig. 3. PSO Algorithm 
$P S O$ [3] is a bio-algorithm inspired by flocks of birds. In principle, for each $t$ instant, each swarm particle $i$ moves around an $n$-dimensional searchspace, finding the problem optimal solution. These movements are guided by velocity $V_{i}^{t}$, which updates depending on the best known local position Pbest $_{i}$, and the best known global position Gbest. Figure (3) summarizes the PSO algorithm.

\section{Table 2: PSO Coeffiecients}

\begin{tabular}{llll} 
Coefficient & Value & Coefficient & Value \\
$c_{1}$ & 2.05 & $\bar{\omega}_{\min }$ & 0.40 \\
$c_{2}$ & 2.05 & $\bar{\omega}_{\max }$ & 1.40 \\
$\chi$ & 0.73 & & \\
\hline
\end{tabular}

To improve the algorithm's performance, this version of the PSO safely initializes position $x_{i}$ starting in a feasible region. Also, two modifications to the standard velocity update $V_{i}^{t+1}$ were used (Table 2): inertia weight $\omega$ [4] and constriction coefficient $\chi$ [5].These amendments guarantee PSO convergence and avoid the use of maximal velocity. A dynamic $\omega$ was chosen to balance exploitation and exploration: in the first iterations, it facilitates exploration $(\omega>1)$, while in the last iterations, it facilitates exploitation $(\omega<1)$. This behavior is shown in equation (7). For instance, for the $i-t h$ particle:

$$
\begin{aligned}
& x_{\mathrm{i}}=\text { random } *\left(x_{\mathrm{i}}^{h^{2}}-x_{\mathrm{i}}^{\mathbb{R}}\right)+x_{\mathrm{i}}^{\mathbb{R}} \\
& V_{i}^{t+1}=\chi *\left(\bar{\omega} * V_{i}^{t}+c_{1} * r_{1} *\left(\text { Pbest }_{i}-x_{i}\right)+c_{2}\right. \\
& \left.* r_{2} *\left(\text { Gbest }-x_{i}\right)\right) \\
& \bar{\omega}_{i}=\bar{\omega}_{\max }-\frac{\bar{\omega}_{\max }-\bar{\omega}_{\min }}{F_{\max }} * F_{i}
\end{aligned}
$$

Where $c_{1}$, and $c_{2}$ are the cognitive and collective coefficients respectively, $\omega_{\min }$ and $\omega_{\max }$ are the end points of the interval for which $\omega$ is defined, $F_{\max }$ is the maximal number of iterations allowed, and $F_{i}$ is the number of iterations at the $i-t h$ cycle. The coefficient selection was made according to the literature [4]-[6]. For the position update $x_{i}^{t+1}$, equation (8) was used:

$$
x_{i}^{t+1}=x_{i}^{t}+V_{i}^{t}
$$

Once the position update is completed, a new particle fitness is computed and Pbest and
Gbest are updated. This cycle continues until the maximal allowed number of iterations is reached or until the convergence criterion is met.

\subsubsection{Genetic Algorithms - GA}

GA [7] is a bio-algorithm based on genetics and evolution. GA initializes a random population of $S$ chromosomes in a binary solution of length $\mathrm{L}$. Each iteration-generation, the chromosomes cross over and mutate. However, each binary number must be converted to a decimal $\mathrm{x} \_10$ to obtain an $\mathrm{x}$ array of continuous and measurable numbers (decoding), by equation (9).

$$
x_{i}=x_{10} * \frac{\left(x_{i}^{n}-x_{i}^{n}\right)}{2^{L}-1}+x_{i}^{n}
$$

Each generation, some chromosomes $\left(S_{\text {keep }}\right)$ are selected to breed a new generation and others are discarded $\left(S_{\text {discarded }}\right)$. This selection is based on a fitness score process, where each individual has a fitness $s_{\text {ratio }}$, to be selected. This value is proportional to the ScaledFitness that is achieved by performing a normalization process using the fitness of the fittest discarded chromosome $\left(\right.$ Fitness skeep $\left.+1_{1}\right)$. In this case, the selection method used was the roulette wheel method.

$$
\begin{aligned}
& \text { ScaledFitness }_{\mathrm{i}}=\text { Fitness }_{\mathrm{i}}-\text { Fitness }_{\text {Sheep }+1} \\
& \text { Fitness }_{\text {Ratio } \mathrm{i}}=\frac{\text { ScaledFitness }_{\mathrm{i}}}{\left(\sum_{I=0}^{l=S_{\text {lass }}} \text { ScaledFitness }_{i \mathrm{i}}\right)}
\end{aligned}
$$

GA has two basic operators: crossover (a convergence operation) and mutation (a divergence operation). Crossover is intended to pull the offspring and only depends on the parents' information and on the number of crossover points. In this case, we used a one-point crossover, the mutation operator, on the other hand, avoids the convergence of the individuals to a local optima, randomly modifying a percentage $\mu$ of bits in each generation, so that the total number of mutations is given by equation (12):

$$
M=\mu * S * n * L
$$

\subsection{Simulator}

The simulator module is an ordinary differential equation module based on the $4^{\text {th }}$-Order Runge Kutta Method [8,9], which simulates a machine's dynamic response without building prototypes. It can be replaced by Dormand Prince or another suitable numerical solution method. 


\subsection{Machine model: Swash plate axial piston pump}

The machine model module contains the equations that represent the desired machine to be designed, in this case, a fixed displacement swash plate axial piston pump. It was built based on several studies [1], [10-22] and the modifications made by the authors of this paper.

The optimal design must: minimize the pump volume, maximize efficiency, and minimize two types of noise: structure-borne noise (SBN) and fluid-borne noise (FBN). To achieve this goal, the model was split into two parts.

\subsubsection{Machine module: Pump optimization first Stage model}

The machine module uses the stated equations to yield the dimensions for the pump rotating group, which is comprised of the drive shaft piston, cylinder block, swash plate and port plate. Piston diameter is found by analyzing the barrel critical section [15]. Contiguous chamber pressure forces are calculated as shown in Figure (4).

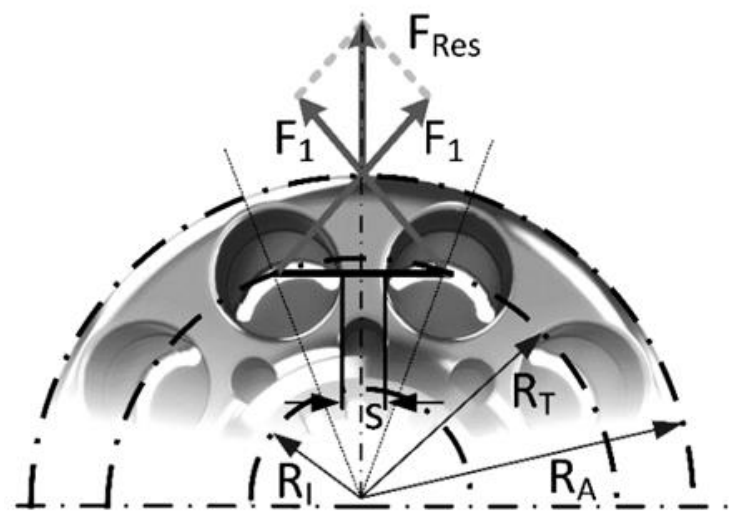

Fig. 4. Barrel Main Forces and Dimensions. Adapted from [15]

$$
d_{K}=\sqrt{\pi * \tan \beta * Z *\left(2 * p * \frac{\sin \left(\frac{360^{\circ}}{4 * Z}+45^{\circ}\right)}{\sigma}+1\right)}
$$

Then, it is possible to find the cylinder block representative radius using equations $(14,15$, and 16).

$$
\begin{gathered}
R_{T}=\frac{2 * v_{g}}{p i * d_{k}^{2} * \tan (\beta) * z} \\
R_{0}=R_{T}+s+d_{k} / 2 \\
R_{i}=R_{T}+s-d_{k} / 2
\end{gathered}
$$

Where $R_{0}, R_{i j}, R_{T}$ are the exterior, interior, and piston pitch radiuses of the barrel.

Thereafter, the shaft minimum diameter $D_{S}$ is computed using the Goodman line equation, which requires a predetermined safety factor, NSF, and a material maximum resistance factor. Figure (5) shows an analysis of the shear and bending moments.

$$
\begin{gathered}
D_{s}=\sqrt{\left(32 * \frac{M b}{\pi}+\sigma_{s} * \sqrt{3} * \frac{16 * M t}{S_{\text {uts }} * \pi}\right)} \\
*\left(\frac{N_{s f s}}{\sigma_{s}}\right)
\end{gathered}
$$

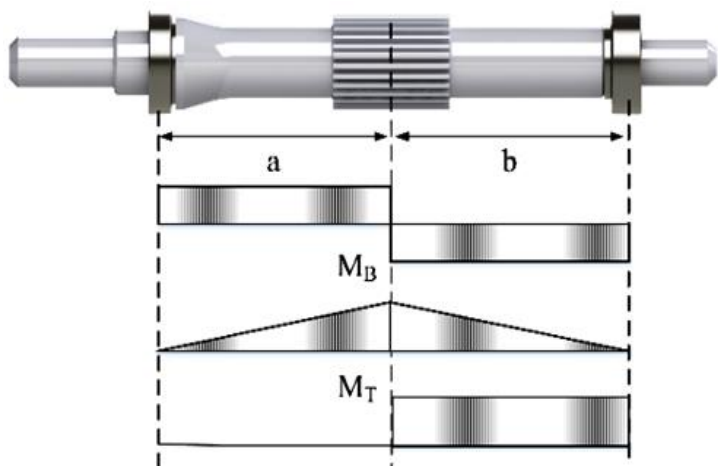

Fig. 5. Shear and Bending Moments

Subsequently, a piston force assessment is performed using a free body diagram (Figure 6). The piston main force is the radial force that is exerted upon the piston head. It can be computed using equation (18).

$$
\sigma_{\max }=\frac{6\left[F_{R K \max } *\left(l_{0}+\frac{l_{K}}{2}\right)\right]}{d_{K} * l_{K}^{2}}+\frac{F_{R K \max }}{d_{K} * l_{K}}
$$

Once the piston maximum stress $\sigma_{\max }$ is computed, a penalization evaluation process can be conducted based on the restrictions. The following equations $(19,20,21$, and 22) are 4 of 12 restrictions proposed due to the subparts' assembly geometry and their material resistance.

$$
\begin{gathered}
R_{1_{1 s}}=1.5 \leq\left(\frac{L_{k}}{d_{k}}\right) \leq 2.5 \\
R_{2_{1 s}}=L o \geq H_{k} \\
R_{a_{2 g}}=D s \leq D i \\
R_{4_{y s}}=\sigma_{k} \geq \sigma_{\max }
\end{gathered}
$$




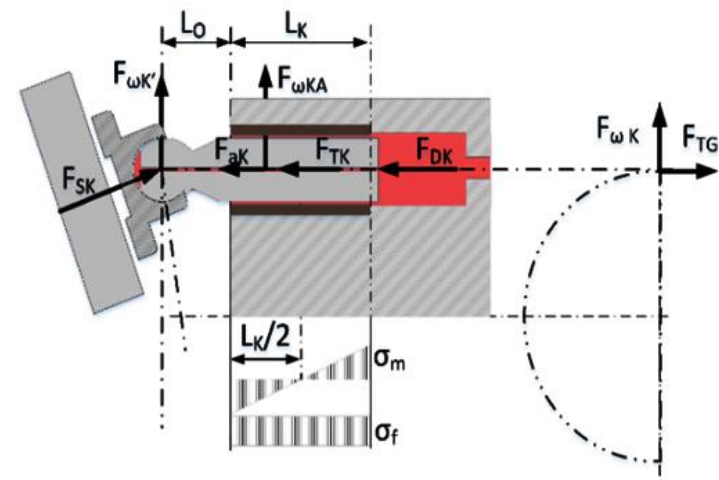

Fig. 6. Piston Main Forces. Adapted from [15]

Finally, the objective function is evaluated (equation 23) and a penalized fitness is calculated (equation 24). This result includes the barrel volume minimization (since it is proportional to that of the pump) and the swash plate angle maximization.

$$
\begin{gathered}
O F_{1 s}=\frac{\pi}{4} *\left(D_{\mathbb{\alpha}}^{2}-D_{i}^{2}\right) *\left(H_{k}+L_{k}\right)-\beta \\
O F p_{1 s}=O F+\sum_{i=1}^{I_{\operatorname{minax}}} \alpha * R_{\hat{I}}
\end{gathered}
$$

\subsubsection{Machine module: Pump optimization second stage model}

The second stage model is based on the equations for port plate design. The model includes the pump's dynamic response: its pressure profile, moments profile, and forces profile. It also accounts for compressibility and density changes depending on the piston chamber's and discharge chamber's pressures and temperatures (assumed constant for optimum design). In this stage, the objectives are to minimize flow leakages $Q_{l k}$, and to minimize $S B N$ and $F B N$.

Piston position, stroke, velocity, and acceleration are given by equations $(25,26,27$, and 28$)$, respectively.

$$
\begin{gathered}
s_{k}=-R * \tan (\beta) *(1-\cos (\varphi)) \\
H_{k}=2 * R * \tan (\beta) \\
v_{k}=-\omega * R * \tan \beta * \sin \varphi \\
a_{k}=-\omega^{2} * R * \tan \beta * \cos \varphi
\end{gathered}
$$

To compute piston chamber pressure, the differential equation (30) is used. It considers pressure as constant in the space domain but not in the time domain.

$$
\begin{gathered}
\frac{d p_{D C}}{d t}=\frac{K}{V} *\left(Q r+Q_{a k}+Q_{a B}+Q_{S G}-\frac{d V}{d t}\right) \\
K=\frac{1}{B_{p}\left(\rho_{v} T\right)}=\frac{\rho(T)\left(a_{2} * a_{a} * T+p\right)}{a_{1} \rho\left(p_{s} T\right)} \\
\rho(T)=r_{S}\left(1-a_{i s} * T\right) \\
\rho(p, T)=\frac{\rho(T)}{1-a_{1} * \ln \left(\frac{a_{2}+a_{a} * T+p}{a_{2}+a_{a} * T}\right)}
\end{gathered}
$$

Where $K$ is the fluid bulk modulus, which depends on the piston chamber's pressure and temperature (Eq. 30A, 30B, and $30 \mathrm{C}$ ). Using an HLP32 fluid, the constant values are $a_{1}=0.07329654, a_{2}=1965.018$ bar, $_{2} a_{2}=$ $-2.968126 \mathrm{bar} / K_{s} r_{g}=1047.03 \mathrm{~kg} / \mathrm{m}^{\mathrm{a}}{ }^{\mathrm{a}} a_{\text {lls }}=$ $0.00057616681 / K_{x}$

[17].

$Q_{S K}, Q_{S B}, Q_{S G}$ are the leakages (Figure 7) through 3 lubricating gaps: the piston to cylinder block, cylinder block to valve plate, and slipper to swash plate gaps, respectively [15]. $Q_{r_{i}}$ is the sum of the flow rates between the $i^{\text {th }}$ chamber and the pump ports [17]. Since leakages mainly depend on gap height, the optimum leakage is given by the optimum gap height. For example, for the piston to cylinder block, optimum gap height $h_{k}$ is given by equation (31) [15].

$$
h_{\mathrm{k}}=1.414 \sqrt{\mu * I_{\mathrm{k}} * \omega * R * \tan (\beta) \sin (\varphi) * \frac{1}{P_{\mathrm{i}}-P_{\text {case }}}}
$$

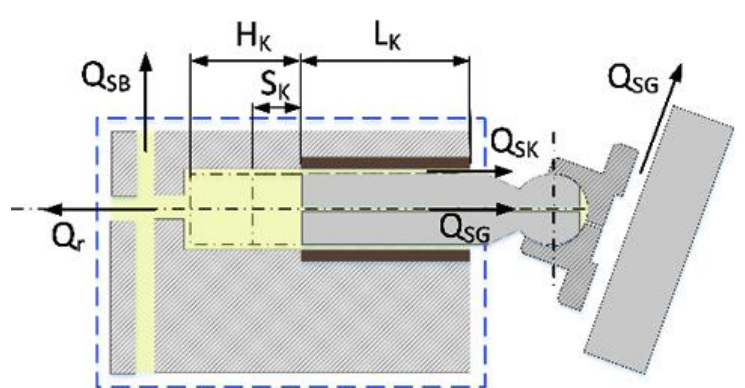

Fig. 7. Piston Leakages. Adapted from [15]

The fluid volume, $V$, inside a chamber can be computed using (equation 32):

$$
V=V_{0}-R * \tan (\beta) *(1-\cos \varphi) * A_{\mathbb{k}}
$$

The change of the volume over time, $d V / d t$, is given by (equation 33): 


$$
\frac{d V}{d t}=V_{k} * A_{K}
$$

Where $V_{O}$ is the fluid volume when the piston is at top dead center (TDC).

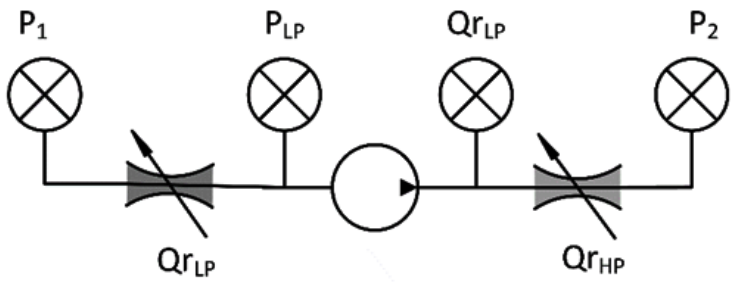

Fig. 8. Schematic of the axial piston pump with the connected lines. Adapted from [23]

The suction and discharge flow rates were simulated using the turbulent orifice (Figure 8) equations (34) and (35).

$Q r_{L P}=\alpha_{L P} * A r_{L P} \sqrt{\frac{2}{\rho}} \sqrt{\left|\mathrm{p}_{1}-\mathrm{pr}_{\mathrm{LP}}\right|} * \operatorname{sgn}\left(\mathrm{p}_{1}-\mathrm{pr}_{\mathrm{LP}}\right)$

$Q r_{H P}=\alpha_{L P} * A r_{L H} \sqrt{\frac{2}{\rho}} \sqrt{\mid \mathrm{p}_{2}-\mathrm{pr}_{\mathrm{HP}}} * \operatorname{sgn}\left(\mathrm{p}_{2}-\mathrm{pr}_{\mathrm{HP}}\right)$

Where $\alpha_{L p}$ and $\alpha_{H P}$ are the discharge coefficients. It is assumed that $\alpha_{L p}=\alpha_{H P}=0.675 . A r_{L P}$ and $A r_{L H}$ are the valve plate opening areas for flow transfer between the chamber and the pump ports. $p r_{H P}$ and $p r_{L P}$ are the discharge port pressure and suction port pressure, respectively, while $p$ is the chamber pressure.

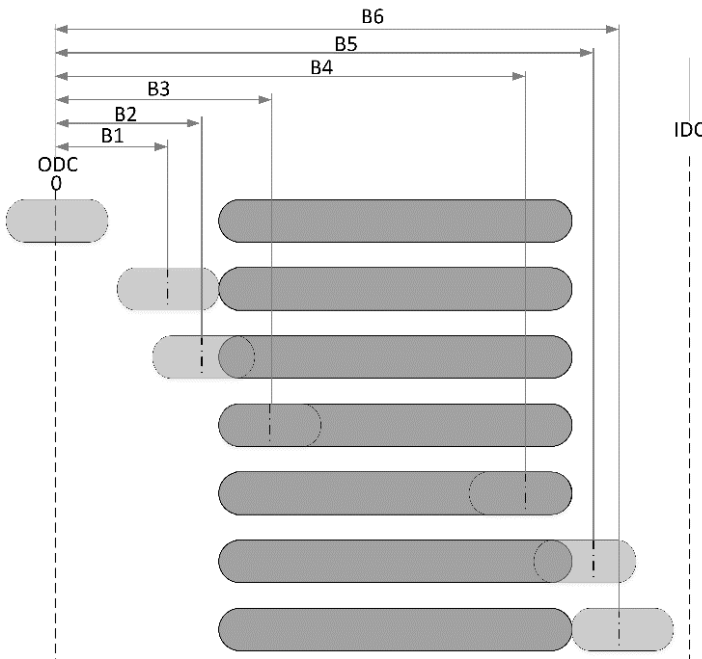

Fig. 9. Linear Kidney Port Linear Model
In this work, we analyze the effect of using the Ideal Timing Technique. To get the effective kidney port area $\left(A_{r}\right)$, we defined 6 angles for each kidney port. These angles are measured from TDC to the piston chamber orifice center, as is shown in Figure (9). The area definition is specified using a linearized kidney model, as follows:

$$
\begin{gathered}
\text { if } D C_{\text {start }}<\varphi \leq B_{1}: \\
A r=0 \\
\text { if } B_{1}<\varphi \leq B_{2}: \\
A r=r_{c}^{2} *\left(2 * \theta_{5}-\sin \left(2 * \theta_{5}\right)\right) \\
\text { if } B_{2}<\varphi \leq B_{a} \\
A r=\pi * r_{c}^{2}+2 * r_{c} *\left(\varphi-B_{2}\right) * R \\
\text { if } B_{2}<\varphi \leq B_{4} \\
A r=2 * r_{c} * l_{c}+\pi * r_{c}^{2} \\
\text { if } B_{4}<\varphi \leq B_{5} \\
A r=2 * r_{c} *\left(l_{c}-\left(\varphi-B_{4}\right) * R+\pi * r_{c}^{2}\right. \\
\text { if } B_{5}<\varphi \leq B_{6} \\
A_{r}=r_{c}^{2} *\left(2 * \theta_{5}-\sin \left(2 * \theta_{5}\right)\right) \\
\text { if } B_{6}<\varphi \leq D C_{e n d} \\
A r=0
\end{gathered}
$$

Where $r_{c}$ is the curvature ratio and $l_{c}$ is the piston chamber opening center distance. $D C_{\text {start }}$, and $D C_{\text {end }}$ are the angular positions at which the chamber starts and finishes contacting the port.

According to [23], to model the system pressure caused by the charge, a virtual throttling valve can be used at the pump inlet and outlet (equations 43 and 44). This strategy allows sufficient equations for pressure simulation. In this case, low pressure is assumed as a constant.

$$
\begin{gathered}
\frac{d p_{H P}}{d t}=\frac{K_{H P}}{V_{H P}} *\left(Q r_{H P}-Q_{\text {out }}\right) \\
\frac{d p_{L P}}{d t}=0
\end{gathered}
$$

Where $K_{H P}$ is the instantaneous fluid bulk modulus at the discharge chamber, which is calculated using equations (30A, 30B, and 30C). $V_{H P}$ and $V_{L P}$ are the discharge port and suction port volumes, respectively. These values depend on the manifold geometry. $Q r_{H P}$ and $Q_{\text {out }}$ are the discharge port inlet and outlet flow rates. $Q r_{H P}$ is computed by summing the piston discharge flow rates (equation $45)$.

$$
Q r_{H P}=\sum_{i=0}^{Z} Q r_{H P_{i}}
$$


To compute $Q_{\text {out }}$, a modification of equation (34) is used (equation 46). The throttle valve area, $A_{H P_{T V}}$,was calculated using a mathematical regression.

$Q_{\text {out }}=\alpha_{T V} * A_{H p_{N V}} \sqrt{\frac{2}{\rho}} \sqrt{\left|\mathrm{p}-\mathrm{pr}_{\mathrm{HP}}\right|} * \operatorname{sgn}\left(\mathrm{p}-\mathrm{pr}_{\mathrm{HP}}\right)$

To sum up, this model considers a total of 10 ODE ( 1 for each piston and 1 for the discharge port pressure) that must be solved simultaneously with the other normal equations. This allows for the computation of the instantaneous pressure at each piston chamber and at the discharge port, taking into account the compressibility of the working fluid. For this stage, the objectives were to minimize flow leakages $Q_{l k}$, and to minimize the noise sources $S B N$ and $F B N$. There are 8 decision variables; 4 angles each for both kidney ports. Restrictions are used so that there is no overpressurization or cavitation. In this phase, we use the same penalized model as in the first optimization stage.

$$
\begin{gathered}
O F_{25}=\operatorname{minimize}\left(\Delta Q_{H p}, \Delta Q_{1 k}, \Delta M_{x}, \Delta M_{x}, \Delta M_{y}, \Delta M_{z}\right) \\
=(x) \\
\text { Where } x=\left[B_{1}, B_{2}, B_{2}, B_{4}, B_{5}, B_{6,}, B_{7,}, B_{\mathbb{Q}}\right] \\
O F p_{2 s}=O F_{2 s}+\alpha * R_{C}+\alpha * R_{O P} \sum_{i=1}^{I_{\text {fmax }}} \alpha * R_{2 g_{i}}
\end{gathered}
$$

Where $R_{c}$ is proportional to the difference between the minimum pressure and the cavitation pressure. $R_{O P}$ is proportional to the difference between the maximum pressure and the operating pressure. $R_{2 s_{i}}$ are the restrictions due to the decision variable limits.

\subsection{Computational framework architecture and methodology}

A multi-level scheme of $\mathrm{C}++$ template-based classes was developed. The SMEDT has 11 classes and 4 structures (also referred to as "objects", which are organized hierarchically as shown in Figure (2) .The optimization manager $(O M)$ is the main object since it sets and manages the optimization process tasks. It also allows for data input and output, and for setting user preferences. The simulation manager $(S M)$ is the secondary object and allows for simulation method changes. For a better understating of SMEDT operations, the first and second stage optimizations are depicted in Figure (10).

The OM selects PSO or GA depending on the user's choice. Then, the optimizer creates an initial random-safe population. Thereafter, each of the particles or chromosomes evaluates its solution on the pump model. For this operation, the simulator computes the pump's dynamic response and thereby captures flow and pressure oscillations. This finished, the simulator checks if there is cavitation or over-pressurization, then computes the penalized objective function and continues this cycle until the optimum solution is found or the maximum number of iterations is reached. This process is performed 4 times, one for each operating point. The final four optimal designs are evaluated with respect to the other 3 operating points to guarantee that they still satisfy the design restrictions. Finally, the best design is selected by comparing each design's 4 operating point penalized fitness.

\section{SIMULATION AND RESULTS}

To validate the efficiency of the SMEDT, an optimization of the pump's design was conducted varying the operating pressure and operating angular velocity. This creates an operating range that is framed by 4 critical operating points, as shown in Figure (10).

\section{Table 3: Pump Specifications}

\begin{tabular}{llll}
\hline Pmax & Pmin & nmax & nmin \\
$330[\mathrm{bar}]$ & $230[\mathrm{bar}]$ & $2000[\mathrm{rpm}]$ & $1200[\mathrm{rpm}$ \\
\hline
\end{tabular}

The minimal and maximal pressure and velocity values are shown in Table (3). This section is divided into two parts to independently analyze the influence of the optimizer algorithm and its number of iterations on the first stage of the study case, and to analyze the SMEDT's overall performance on the sustainable design of a fixed displacement swash plate type axial piston pump. 


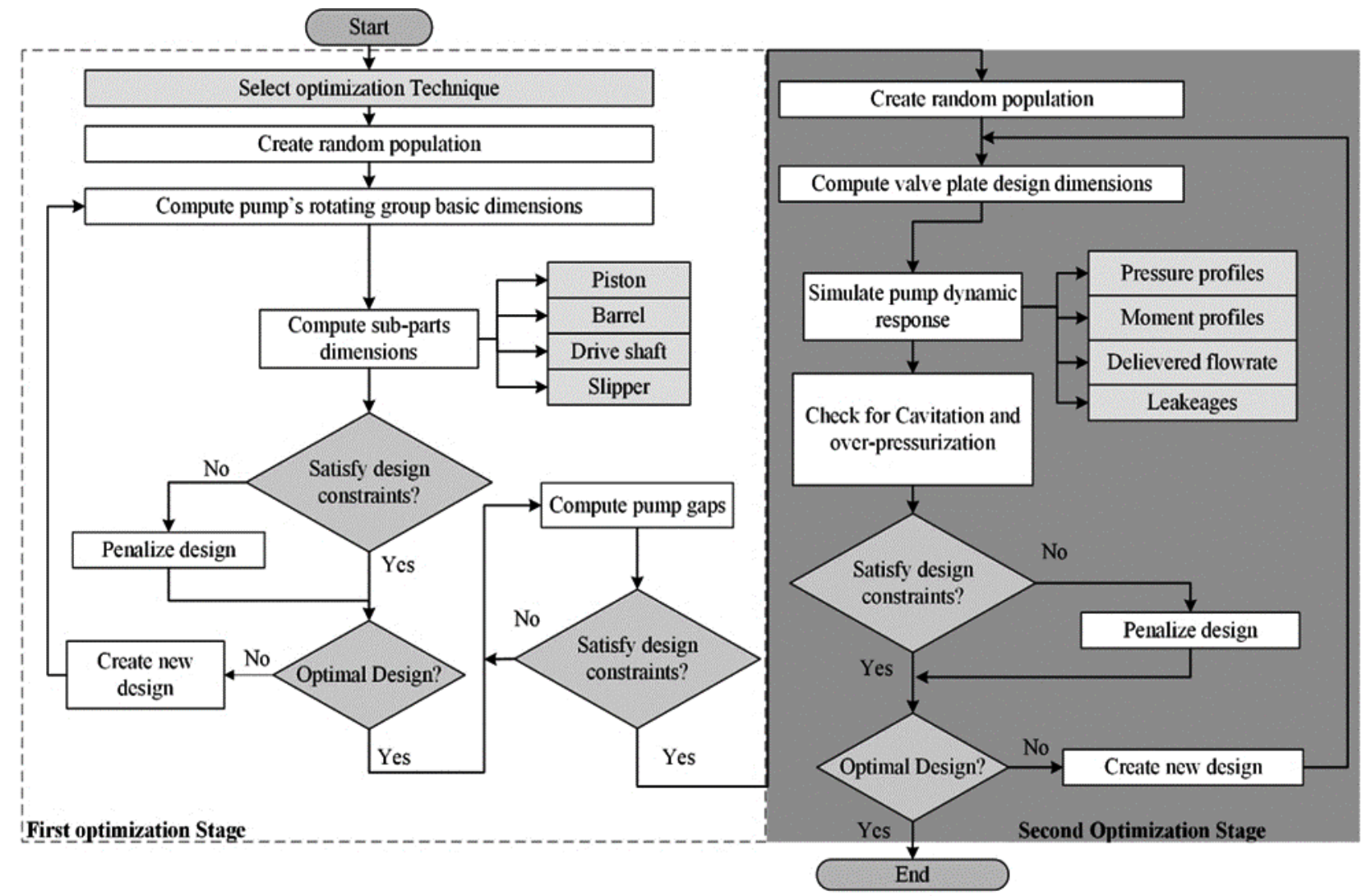

Fig. 10. SMEDT Algorithm

\subsection{GA and PSO results comparison}

In this section, we performed only the first stage optimization - since it is the less time-consuming of the two - using GA and PSO at 100 and 1000 iterations each. The process was repeated 10 times to find the deviation of the results. The pump and the optimization parameters are shown in Tables (3) and (4).

\section{Table 4: Optimization Algorithm Specifications}

\section{Iter.} Part / Chrom

Selection

\begin{tabular}{lllll}
\hline$P S O$ & $100-1000$ & 20 & N/A & N/A \\
\hline GA & $100-1000$ & 50 & Roulette & 0.8 \\
\hline
\end{tabular}




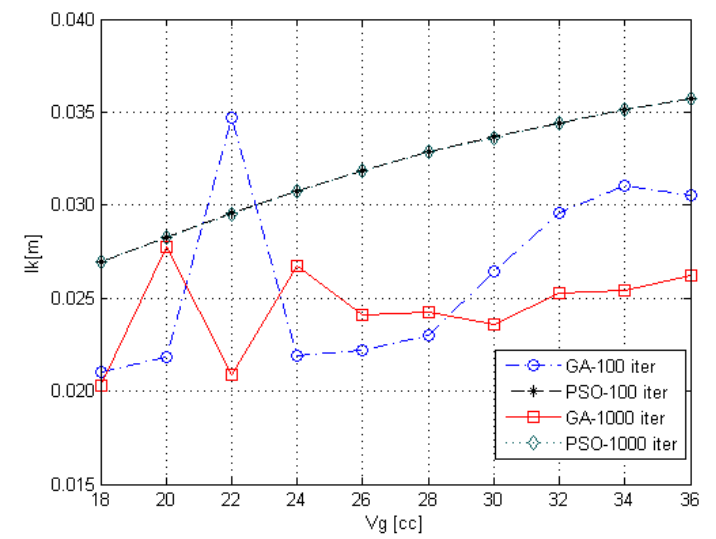

Figure 12. Change of Optimum $l_{k}$ varying $V_{g}$

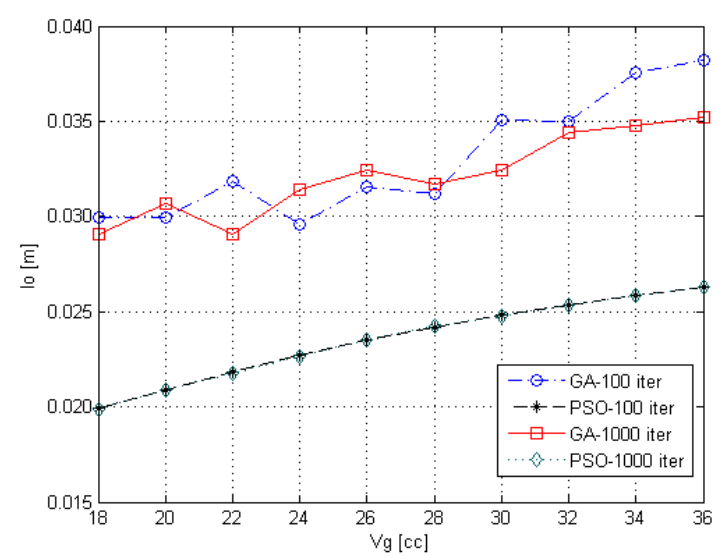

Figure 13. Change of Optimum $l_{0}$ varying $V_{g}$

The results (Figure 11, 12 and 13) showed - more clearly in the case of PSO - a tendency to increase the decision variable values with the increase of the displacement volume. In the case of GA, the average fitness for the 100 iteration test is -9.32 . This fitness value also has a high deviation. When increasing the number of iterations to 1000 , the fitness improves to a value of $-12,45$ and the oscillations decrease about $20 \%$. In the case of PSO, the results at 100 iterations and 1000 iterations show an average fitness of -22.54 , with deviations lower than $0.001 \%$ and $0.000001 \%$, respectively.

\section{Table 5: Full Pump Design Parameters}

\section{Operating Conditions}

Magnitude

Maximum Operating Pressure [bar]

330

Min. Operating Pressure [bar]

Max. Operating Angular Velocity

[RPM]

Min. Operating Angular Velocity

[RPM]

Displacement Volume $V_{g}$ [cc]
Number of Pistons Z

9

\subsection{Pump full design using PSO}

In this section, the results of the full optimal design of the swash plate axial piston pump are shown to validate SMEDT efficiency. The design parameters are shown in Table (5).

Since the first optimization only takes into account the mechanical design, the optimization process is performed only on the most critical operating points (i.e. maximum pressure and maximum angular velocity) where the stresses on the components are at their maximums. The results of this stage are shown in Table (6).

\section{Table 6: First Stage Results: Main Dimensions}

\section{Design Parameters}

Magnitude

Swash Plate Angle $\beta\left[^{\circ}\right]$

19

Piston Diameter $D_{k}[\mathrm{~mm}]$

Piston Pitch Radius R [mm]

Length of Piston Shirt $l_{k}[\mathrm{~mm}]$

28

Piston Outstanding Length in ODC $l_{。} 21$

Total Piston Length $l_{z}[\mathrm{~mm}]$

On the other hand, the second optimization stage takes into account the four (4) critical operating points to guarantee good performance along the whole operating range. The results for each operating point are shown in Table 7. The second stage total computation time was 24 hours.

\section{Table 7: Port Plate Optimal Design at the 4 Oper.}

\section{Points}

\begin{tabular}{lllll} 
Operating & \multicolumn{2}{c}{ Discharge Port } & \multicolumn{2}{l}{ Suction Port } \\
Point & Start & End & Start & End \\
\hline 1 & 17.83 & 153.91 & 188.55 & 330.97 \\
2 & 20.54 & 158.22 & 191.01 & 331.26 \\
3 & 14.56 & 157.23 & 189.09 & 331.03 \\
4 & 18.89 & 158.52 & 190.23 & 331.59 \\
\hline
\end{tabular}

\section{DISCUSSION}

In this paper, the performance of the modular computational framework SMEDT for achieving a sustainable mechanical design for any machine was demonstrated by analyzing as a study case the design of a fixed displacement swash plate axial piston pump and varying the optimization method. 
The tests were performed taking into account the holistic machine behavior over an operating range and not only at a single point. This research also validated the efficiency of the GA and PSO methods for optimizing a mechanical design.

To guarantee the accuracy of the SMEDT, a divide-and-conquer test approach was taken; that is, individual tests were performed separately for each framework module [24]. To demonstrate the effectiveness of the GA and PSO optimization algorithms, we used six test problems [25]. There, PSO showed differences smaller than $2 \%$ over the best solution on each of the test problems; whereas GA resulted in differences smaller than $7 \%$ compared to the best solution. Following the same scheme, the simulation module was tested on four problems [8]. The results showed consistency with the ones arrived at using MATLAB.

For the machine module evaluation, the results obtained in the two-stage optimization approach (Figure 14 and 15) were compared to those from the literature [1], [17]. For the first stage, the comparison was made using a Purdue University graduate thesis [1], and in spite of that fact that our model does not include a complete pump barrel force assessment, the results showed differences smaller than $3 \%$ in all the basic dimensions of the rotating group. It was found that to increase accuracy, especially when the discharge pressure is low, it is recommended to add design constraints due to the movement restriction imposed by the geometry of the slipper piston assembly.

Besides the above caveat, the results behaved as expected and the influence of the piston inertial force and centrifugal force are minimal, especially on small pumps. It was found that for $24 \mathrm{cc}$ pumps working at $330 \mathrm{bar}$, the first optimization decision variables do not appear to depend on the angular velocity at which the pump is working. This is because, although there are three forces acting on the piston, the pressure force impacts mostly upon the size of the rotating group. For example, in the case of the swash plate angle, the choice of whether to include or exclude centrifugal and inertial forces resulted in a difference of less than $0.5^{\circ}$. Such a variance has no influence on the final design because the normalization process compensates for it. From the above, we can conclude that the results obtained are consistent with expectations for the pump's mathematical model [26].
The optimization methods used to solve the first stage were also compared for 100 and 1000 iterations. It was found that PSO showed a better response in both cases. This suggests that PSO is a good choice for solving engineering problems even with few iterations, which is a reflection of a good balance between exploration and exploitation. This efficiency translates into a reduced requirement for computing time (about 60\% less). Conversely, GA seems to get trapped in local optima (which violate some design constraints) and thus it insufficiently explores the search space. GA also shows a strong dependence on the number of iterations and the chosen mutation factor. To address this finding, we are currently performing a study of the sensitivity of PSO and GA parameters on the design of the pump and other industrial machines using a parallel PSO and GA parameters optimization stage based on the Simplex method [27].

Regarding the second optimization stage (port plate optimization), to ensure more reliable and consistently realistic results, we include an embedded simulation process in each optimization cycle to capture variations in fluid density and compressibility (dependent on pressure and temperature), and the delivered and lost flows (dependent on the geometry of the plate ports), Since previous studies [17] do not show all the optimization parameters, a complete numerical comparison is not possible. However, this study did compare the dynamic response of the pump to that found in the literature, finding a remarkable consistency in the shape and size of the ripples in the graphs of pressure, flow discharge, and 3 axis moments. To increase the depth of the analysis, we are working on a CFD module that will allow us to fully characterize flow loss clearances.

The good performance of our application make it an appropriate supportive decision-making tool for sustainability. In the current study, the criterion for sustainability in the first stage was the reduction of the pump size for a specific operating range to reduce consumable resources required [28]. In the second stage, it was the improvement of the overall efficiency to decrease energy consumption. However, other sustainable criteria could be additionally integrated into the SMEDT, for example, design optimization for manufacturing. 

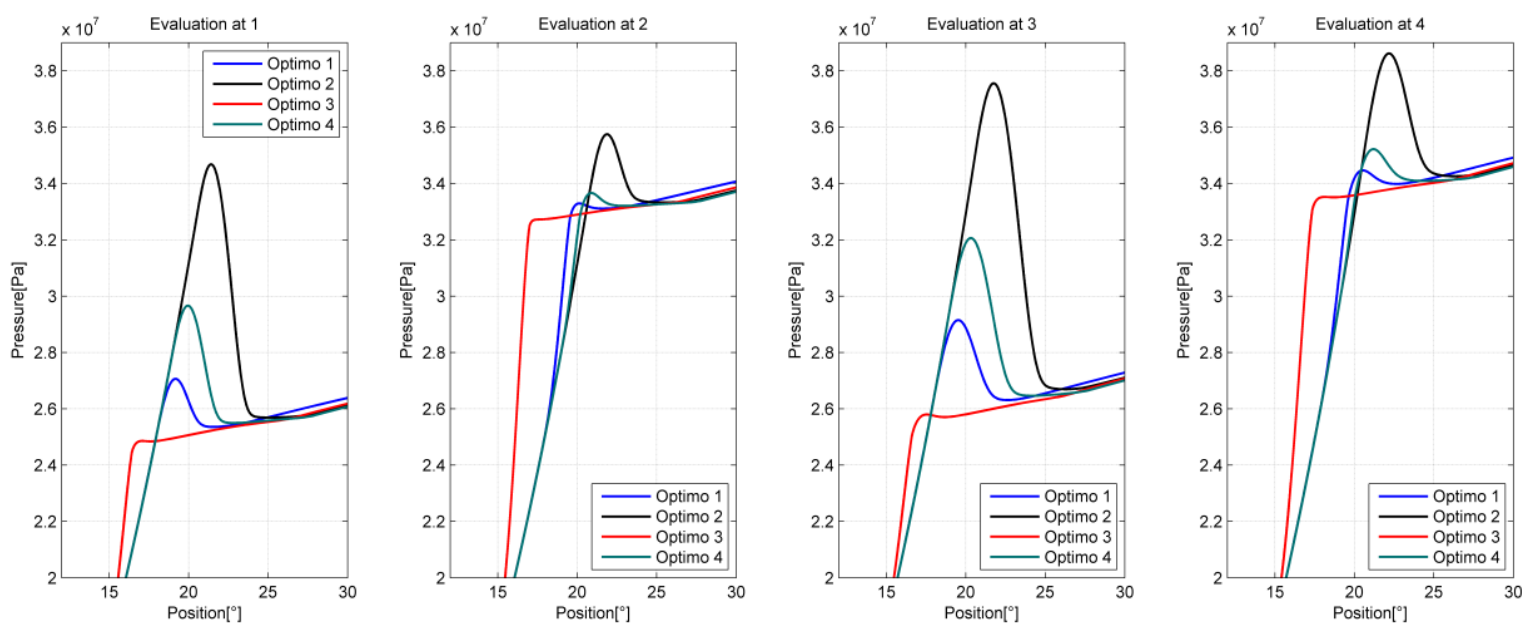

Figure 14. Optimal Designs' Over Pressure Peaks Analysis at Critical Angular Positions
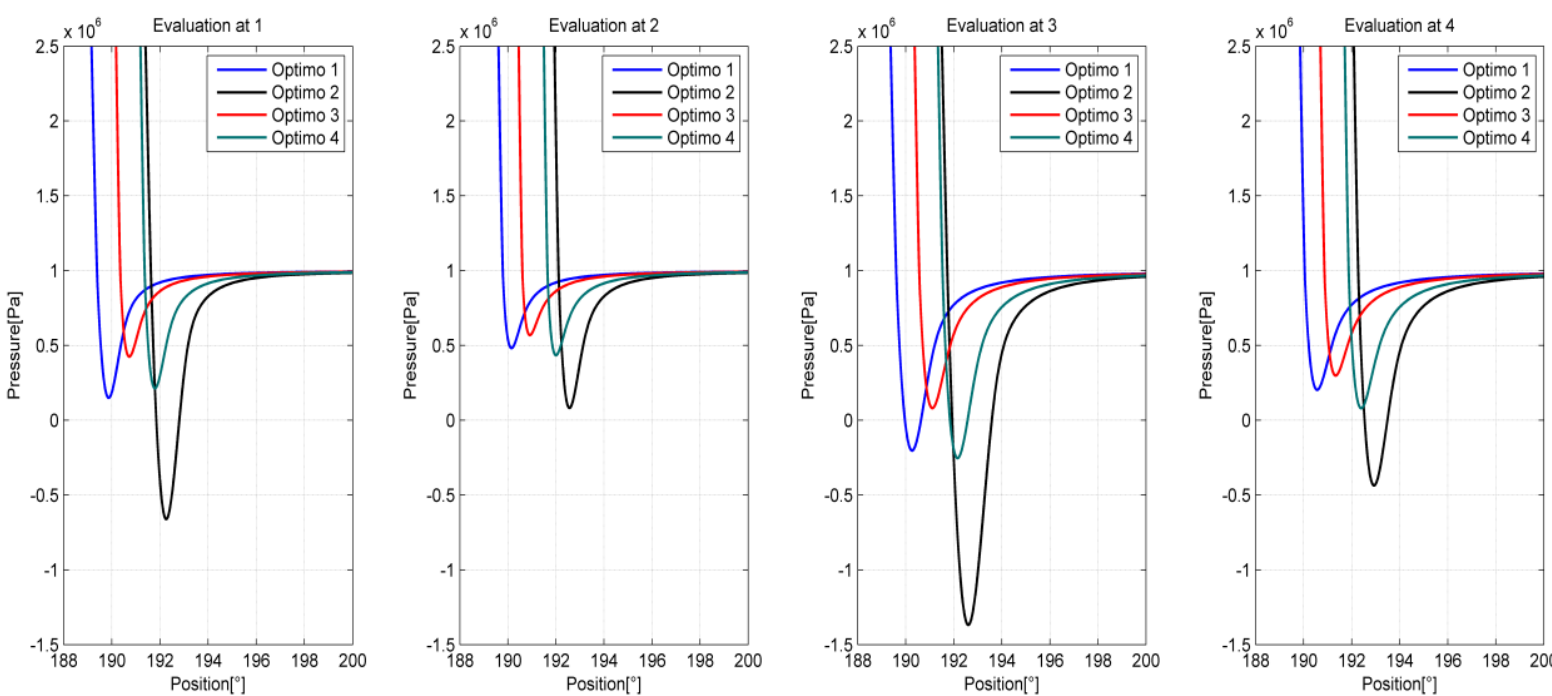

Figure 15. Optimal Designs' Cavitation Analysis at Critical Angular Positions

For the aforementioned reasons, the SMEDT makes possible a revolution in methodology for designing machines and products, as it reduces the need to build prototypes and diminishes associated costs. This implies that commercially sustainable machines can compete on price with less environmentally-friendly machinery. This option would generate an additional incentive for companies to make the transition towards sustainable development of the industry.

\section{CONCLUSION}

To conclude, the computational framework SMEDT substantially improves the design process, allowing for more complex models, as was proved using the design of the swash plate axial piston pump. These improvements have a positive impact on cost, time, precision, and efficiency and occur due to our method's ability to provide quality solutions to constrained multi-objective problems, including problems with an embedded simulation. We observed a considerable advantage for PSO over GA in all of the analyzed aspects. PSO results were always better than GA at both 100 and 1000 iterations. This result occurred because PSO has a larger exploration component than GA. Finally, the convergence of PSO was better because of the use of the Clerc algorithm [5] 


\section{ACKNOWLEDGMENTS}

We wish to express our sincere gratitude to Dr. Oscar Begambre for his guidance on this project. We also thank Vicerrectoria de Investigación y Extensión de la Universidad Industrial de Santander (UIS), for funding this research as part of the project: "Desarrollo de un prototipo de pozo inteligente para Campo Escuela Colorado (8556)".

\section{REFERENCES}

[1] R. Ivantysyn, "Computational design of swash plate type axial piston pumps - a framework for computational design," Purdue University, 2011.

[2] Z. Junhui and X. Bing, "Clearance optimization of piston/cylinder pair based on virtual prototype of axial piston pump," Mechatronics and Embedded Systems and Applications (MESA), 2012 IEEE/ASME International Conference on. pp. 166$171,2012$.

[3] J. Kennedy and R. Eberhart, "Particle swarm optimization," Neural Networks, 1995. Proceedings., IEEE International Conference on, vol. 4. pp. 1942-1948 vol.4, 1995.

[4] Y. Shi and R. Eberhart, "A modified particle swarm optimizer," 1998 IEEE Int. Conf. Evol. Comput. Proceedings. IEEE World Congr. Comput. Intell. (Cat. No.98TH8360), 1998.

[5] M. Clerc and J. Kennedy, "The particle swarm explosion, stability, and convergence in amultidimensional complex space," IEEE Trans. Evol. Comput., vol. 6, no. 1, 2002.

[6] Y. Shi and R. C. Eberhart, "Empirical study of particle swarm optimization," in Proceedings of the 1999 Congress on Evolutionary ComputationCEC99, 1999, pp. 1945-1950.

[7] J. H. Holland, Adaptation in Natural and Artificial Systems, vol. Ann Arbor. 1975.

[8] R. P. Canale and S. C. Chapra, Numerical methods for engineers, Sixth edit., vol. 1, no. 3. New York: McGraw-Hill, 2010.

[9] J. Kiusalaas, Numerical methods in engineering with: Python, vol. 11, no. 2. 2005.

[10] J. M. Bergada, S. Kumar, D. L. Davies, and J. Watton, "A complete analysis of axial piston pump leakage and output flow ripples," Appl. Math. Model., vol. 36, no. 4, pp. 1731-1751, 2012.

[11] J. M. Bergada, J. Watton, and S. Kumar, "Pressure, Flow, Force, and Torque Between the Barrel and Port Plate in an Axial Piston Pump," J. Dyn. Syst. Meas. Control, vol. 130, no. 1, p. 11011, Jan. 2008.

[12] B. O. Helgestad, K. Foster, and F. K. Bannister, "Pressure Transients in an Axial Piston Hydraulic Pump," Proc. Inst. Mech. Eng. , vol. 188 , no. 1 , pp. 189-199, Jun. 1974.

[13] M. Holland, "Design of Digital Pump/Motors and Experimental Validation of Operating Strategies," Purdue University, 2012.

[14] A. Vacca, R. Klop, and M. Ivantysynova, “A Numerical Approach for the Evaluation of the Effects of Air Release and Vapour Cavitation on Effective Flow Rate of Axial Piston Machines," Int. J. Fluid Power, vol. 11, no. 1, pp. 33-45, Jan. 2010.

[15] J. Ivantysyn and M. Ivantysynova, Eds., Hydrostatic pumps and motors.pdf, First Engl. New Delhi-110 019, India: Tech books international, 2002.

[16] M. Ivantysynova and J. Baker, "Power loss in the lubricating gap between cylinder block and," Int. J. Fluid Power, vol. 10, no. 2, pp. 29-43, 2009.

[17] G. Kumar Seeniraj and M. Ivantysynova, "A Multi-Parameter Multi-Objective Approach to Reduce Pump Noise Generation,” Int. J. Fluid Power, vol. 12, no. 1, pp. 7-17, Jan. 2011.

[18] N. D. Manring, "The Discharge Flow Ripple of an Axial-Piston Swash-Plate Type Hydrostatic Pump,” J. Dyn. Syst. Meas. Control, vol. 122, no. 2, pp. 263-268, May 1998.

[19] N. D. Manring, "Designing the Shaft Diameter for Acceptable Levels of Stress Within an AxialPiston Swash-Plate Type Hydrostatic Pump," J. Mech. Des., vol. 122, no. 4, pp. 553-559, Jul. 1999.

[20] N. D. Manring, "Valve-Plate Design for an Axial Piston Pump Operating at Low Displacements," J. Mech. Des., vol. 125, no. 1, pp. 200-205, Mar. 2003. 
[21] N. D. Manring and Y. Zhang, "The Improved Volumetric-Efficiency of an Axial-Piston Pump Utilizing a Trapped-Volume Design,” J. Dyn. Syst. Meas. Control, vol. 123, no. 3, pp. 479-487, Jan. 2000.

[22] S. Wang, "Improving the Volumetric Efficiency of the Axial Piston Pump," J. Mech. Des., vol. 134, no. 11, p. 111001, Oct. 2012.

[23] D. Gronberg, "Prediction of Case Temperature of Axial Pis- ton Pumps," Chalmers University of Technology, 2011.

[24] L. C. Maldonado, R. Tarantino and D. A. Rozo, "Continuous supervising procedure for automatic checking of produced devices," Revista Colombiana de Tecnologías de Avanzada, vol. 2, no. 12. pp. 108-113, 2008.

[25] K. K. E. Parsopoulos and M. N. Vrahatis, "Particle Swarm Optimization Method for Constrained Optimization Problems," Proc. EuroInternational Symp. Comput. Intell. 2002, no. 6, pp. 214-220, 2002.

[26] A. Bocanegra and R. Ochoa, "Nanomachines: past, present and future," Revista Colombiana de Tecnologías de Avanzada, vol. 1. pp. 132-136, 2006.

[27] O. Begambre and J. E. Laier, "A hybrid Particle Swarm Optimization - Simplex algorithm (PSOS) for structural damage identification," Advances in Engineering Software, vol. 40, no. 9. pp. 883-891, 2009.

[28] E. E. Espinel, J. C. Hernández and A. Quintero, "Design and simulation of a prototype of machine for signaling of ways, automated through a mechanical system," Revista Colombiana de Tecnologías de Avanzada, vol. 1, no. 25. pp. 7682, 2015. 